\title{
CAPÍTULO XVII
}

\section{MARCO DEL CONTROL DE CONVENCIONALIDAD DE LOS DERECHOS HUMANOS EN LOS CASOS DE DESPLAZAMIENTO FORZADO EN COLOMBIA}

\author{
Enders Campo Ramírez \\ Abogado, Asesor Jurídico del Ministerio de Defensa Nacional-Departamento \\ Jurídico Integral Dirección de Defensa Jurídica Integral Ejército Nacional de \\ Colombia, Docente de la Universidad Popular del Cesar, Magister en Derecho \\ Administrativo. Correo electrónico: enderscampo@unicesar.edu.co Integrante \\ del grupo de investigación Catedra Carrillo. ORCID https://orcid.org/0000- \\ 0003-1174-9917.
}

\section{Mayyohan Romero Muñoz}

Abogado, Asesor Jurídico del Ministerio de Defensa Nacional-Departamento Jurídico Integral Dirección de Defensa Jurídica Integral Ejército Nacional de Colombia, Magister en Derecho Humanos, Derecho Internacional Humanitario y Derecho Operacional. Correo electrónico: mayyohan87@hotmail.com ORCID https://orcid.org/0000-0001-5468-2104.

\section{Resumen}

El desplazamiento interno y forzado de la población es una situación por la que atraviesan personas en diferentes países, una de las más graves es en Colombia donde los enfrentamientos entre las fuerzas armadas y los insurgentes que han tomado o habían tomado grandes áreas del territorio, provocaron la movilización de la víctimas, quienes no tenían distinción de raza, religión, condición social, esto solo evidenciaba la debilidad del Estado para frenar tales hechos, así como la desorganización e ignorancia de las autoridades en cuanto al cumplimiento de los derechos otorgados a estas personas en diferentes instancias internacionales y nacionales. En ese orden de ideas, el objetivo principal de esta investigación fue analizar el estudio de los criterios de verdad y justicia utilizados por la Corte Interamericana de Derechos Humanos para emitir sus sentencias en las demandas de desplazamiento forzado contra el Estado colombiano y la jurisprudencia del Consejo de Estado en materia de desplazamiento forzado en Colombia y la incidencia del control de convencionalidad en materia de responsabilidad patrimonial del Estado, para lo cual se apoyó en las ideas y opiniones de Saravia (2016), Cuchumbré y Vargas (2008), la Statutos de la Corte Interamericana de Derechos Humanos (1979). La metodología de investigación se desarrolló bajo un enfoque cualitativo, en este se propone un diseño documental dado por un seguimiento académico y jurisprudencial que permitió facilitar la resolución del problema legal planteado; como resultado, el Estado colombiano ha sido juzgado y condenado en distintas oportunidades por la Corte Interamericana de Derechos Humanos; al analizar 
cada una de las sentencias dictadas por esta Corte; fundamentos del Derecho Procesal, también se constató prácticas probatorias no convencionales que son consideradas a juicio de los autores contrarias a los lineamientos jurisprudenciales.

Palabras clave: Corte Interamericana, Derechos Humanos, Desplazamiento Forzado, Estado, Responsabilidad Patrimonial.

\title{
FRAMEWORK OF THE CONTROL OF CONVENTIONALITY OF HUMAN RIGHTS IN CASES OF FORCED DISPLACEMENT IN COLOMBIA
}

\begin{abstract}
The forced displacement of the population is a problem that over time finds itself within a multipolar and differential armed confrontation in the regions; the victims are diverse: they do not belong to an ethnic group, a religion, a class or a specific social group. The weakness of the nation, together with the virtuality of rights and the profound fragility of democracy, as well as the insufficient reparation of the victims, have effects that produce changes and restructuring in local and national cultures. The Inter-American Court of Human Rights bases its judgments on the existence of an unconstitutional state of affairs, given this situation, it is enough to demonstrate that there is a massive violation of human rights. In this vein, this research's main objective was to analyze the study of the criteria of truth and justice used by the Inter-American Court of Human Rights to issue its judgments in the demands for forced displacement against the Colombian State and the jurisprudence of the Council of status on the subject of forced displacement in Colombia and the incidence of conventionality control in matters of patrimonial responsibility of the State, taking into account the block of constitutionality, principle of legality and article 90 of the 1991 Constitution of Colombia, The methodology The research was developed under a Qualitative approach, in which a documentary methodology is proposed given by an academic and jurisprudential tracking that allows to facilitate the resolution of the raised legal problem; As a result, the Colombian State has been tried and convicted on different occasions by the Inter-American Court of Human Rights; when analyzing each of the judgments issued by this Court; the foundations of Procedural Law, we find unconventional evidentiary practices that in our opinion are considered contrary to jurisprudential guidelines
\end{abstract}

Keywords: Inter-American Court, Human Rights, Forced Displacement, State, Patrimonial Responsibility

\section{Capitulo resultado de un proyecto de investigación}

El Marco del Control de Convencionalidad de los Derechos Humanos en los Casos de Desplazamiento Forzado en Colombia. Proyecto financiación con recursos propios, 
semillero de investigación DELLEPIANE adscrito al grupo de investigación CATEDRA CARRILLO, Universidad Popular del Cesar, 2020.

\section{Introducción}

La sentencia T-025 del año 2004, así como toda la jurisprudencia que se surgen de ella, permite establecer un encuentro entre el orden científico y el orden jurídico de la realidad social, que enfrentan los desplazados internos forzados en Colombia, debido a la violación de sus derechos humanos no solo por quienes propiciaron su desplazamiento sino también por parte del Estado, hecho que se demostró al descubrir en los millones de documentos jurídicos presentados la manera como el Estado colombiano y sus gobernantes enfrentaron este fenómeno social.

Estadísticamente se tiene que durante el último semestre se han identificado alrededor de 18.000 desplazados con ocasión al conflicto armado en Colombia. Según la Defensoría, la zona con más personas afectadas es la selvática región del Catatumbo, Norte de Santander, integrado por once municipios, una región rústica considerada como de las más sacudidas de Colombia por la presencia de diferentes grupos criminales, guerrillas y narcotraficantes poseedores de una de las áreas con más cultivos de coca del país, sin embargo, las fuerzas militares de Colombia a través de la ejecución de su misión constitucional de preservar el orden y la seguridad del país actúa eficientemente bajo la teoría de la relatividad del servicio, es decir actúa bajo el mayor alcance operativo y logístico de cubrir todas las regiones del país, no obstante como lo indica la misma teoría de la relatividad del servicio su prestación de seguridad se mide bajo los alcances operativos tácticos que estén a su alcance.

Por lo anterior, en este contexto, muchos ciudadanos han acudido a instancias de la Corte Interamericana de Derechos Humanos para poder obtener algún tipo de reparación por su condición de víctima, connotación suficiente que tiene en cuenta la Corte para condenar al Estado Colombiano su reparación. Sin embargo, se omiten elementos de responsabilidad patrimonial tales como el nexo de causalidad, lo que hace que la imputación del daño sea alejada del principio de legalidad, acercándose a un fallo iusnaturalista basado en verdad y justicia. Desde esta perspectiva, surge la pregunta problema de la investigación: ¿Hasta qué punto se cumple el criterio de justicia 
establecido en la Corte Interamericana de Derechos Humanos cuando se presentan las demandas por desplazamiento forzado ante la jurisdicción colombiana por reparación directa vía judicial cuando en la sentencia está probado el daño y no el nexo causal entre el hecho y la acción del agente estatal? y como propósito fundamental del estudio es analizar los criterios de verdad y justicia que utiliza la Corte Interamericana de Derechos Humanos para emitir sus sentencias en las demandas por desplazamiento forzado contra el Estado Colombiano y la jurisprudencia del Consejo de Estado sobre la temática del desplazamiento forzado en Colombia y la incidencia del control de convencionalidad en materia de responsabilidad patrimonial del Estado, teniendo en cuenta el bloque de constitucionalidad, principio de legalidad y el artículo 90 de la Constitución política de Colombia de 1991; como resultados se encontró que el Concejo de Estado estableció una serie de estándares procesales y probatorios para poder imputar responsabilidad al estado en materia de desplazamiento forzado en Colombia, es decir bajo la teoría de imputación de falla del servicio y que exista un nexo de causalidad por acción u omisión de un agente del estado en el hecho cuestionado.

\section{Fundamentos teóricos}

En el derecho internacional el hecho de traspasar una frontera constituye un acto de múltiples implicaciones en el derecho internacional, ya que mientras los individuos se encuentren en su país de origen se hallan bajo el mandato soberano que ejercen los Estados sobre su población y su territorio (Saravia, 2016), sin embargo, al traspasar las fronteras se convierte en una situación que el país de destino tiene que asumir, debido a que se puede ver como una violación a su soberanía, lo mismo ocurre cuando el desplazamiento forzado es interno es una situación que el Estado debe asumir y enfrentar porque se está violando la soberanía estatal "la cual constituye uno de los principios básicos del derecho internacional público" (Saravia, 2016, p.95).

Ahora bien, el tratamiento de ACNUR con respecto a los individuos que lograban cruzar o no la frontera fue:

El Acnur hizo referencia al término "desplazados bajo el cuidado del Acnur" y actuó bajo diferentes parámetros, por lo que se centró ya no en el reasentamiento de las personas, sino en el proceso de retorno al lugar de origen 
y en la repatriación. En 1972, por solicitud del Consejo Económico y Social de las Naciones Unidas, se encargó de facilitar asistencia a los refugiados que retornaban al sur de Sudán, así como a las "personas desplazadas dentro del país", que eran en su mayoría los integrantes del grupo. (ACNUR, 2007, como se citó en Saravia, 2018).

Ante el crecimiento exponencial de la problemática de desplazamiento ACNUR en relación a sus funciones se ve en la necesidad de ampliar su rango de influencia y competencias operativas, por lo que actualmente se ofrece para la búsqueda y solución de esta problemática, esto se puede observar en sus políticas y lineamientos.

Por lo que en la década de los 80 da un paso adelante dirigiendo sus acciones a actividades que buscan prevenir el desplazamiento forzado, llegando a las zonas de expatriación o a donde se movilizaron los individuos desplazados, para ello, como lo señala Vidal (citado por Saravia, 2018) se hizo uso de la figura de misiones concretas, las cuales evolucionaron con el desarrollo de estándares internacionales que buscaban que los Estados los incluyeran dentro de sus leyes o derecho interno. Además, estuvo acompañada de la pérdida de interés de los Estados por acoger a los refugiados.

Todo esto permitió establecer la responsabilidad de los Estados en cuanto a la protección y el pleno disfrute de los derechos de sus ciudadanos, pero también la creación de la obligación internacional de proporcionar ayuda humanitaria a los individuos que se encuentran en esta condición (desplazados) si sus gobiernos no son capaces de otorgar las condiciones mínimas para conservar su dignidad humana.

Finalmente, en 1992 la Organización de las Naciones Unidas estableció que un individuo en condición de desplazado interno era la:

Personas o grupos de personas que se han visto forzadas a escapar de su hogar repentinamente o inesperadamente, a gran escala, como resultado de un conflicto armado, un conflicto interno, violaciones sistemáticas de derechos humanos o catástrofes naturales o causadas por el hombre y quienes permanecen dentro del territorio de su país. (Naciones Unidas, 1992, párr. 17, como se citó en Saravia, 2018, p.30). 
Por su parte, la responsabilidad patrimonial tiene sus orígenes en Francia, cuando con el Fallo Blanco del Tribunal de Conflictos de 1873 y el Fallo Cadot del Consejo de Estado del 3 de diciembre de 1889, fallos en los que se determinó que cuando existe una falla en el servicio de la actividad estatal que afecta no solo la integridad de las personas sino además su patrimonio, deben indemnizarlos de manera integral, esto emancipó la jurisdicción contenciosa administrativa de la Administración. El Consejo de Estado decidiendo sobre la supresión de un empleo de ingeniero en la administración de Marsella aprovecha la ocasión para declararse competente sin necesidad que el ministro se pronunciara en primera instancia (Paillet,2001, citado en Molina, 2005, p. 60.). Además, se empezó a esbozar sobre los primeros títulos de imputación de responsabilidad del Estado, que con el desarrollo jurisprudencial se pueden identificar en la actualidad: la falla del servicio, el riesgo excepcional, el daño especial, entre otros.

En Colombia, el fundamento constitucional de la responsabilidad patrimonial del estado se encuentra en el artículo 90 de la Constitución Política de Colombia, ya que en aras de cumplir con los principios generales del Estado de proteger y salvaguardar la integridad de los particulares, establece que responderá patrimonialmente por los daños antijurídicos que le sean imputables bajo los parámetros de la doctrina del derecho de daños, esto es, en el marco de los lineamientos de la existencia de un hecho generador del daño, el daño antijurídico y un nexo de causalidad entre estos dos (López, 2013).

Ahora bien, en materia del delito de desplazamiento forzado el Consejo de Estado ha establecido distintos parámetros para imputar la responsabilidad del Estado con base a un régimen de "responsabilidad estatal internacional" y en el Sistema Interamericano de Derechos Humanos, en los cuales se hace una distinción entre los hechos ilícitos internacionales y las violaciones a normas imperativas de derecho internacional de ius cogens, el concepto de ius cogens ha estado en sus orígenes ligado particularmente al derecho de los tratados. Tal como está formulado el ius cogens en el artículo 53 de la Convención de Viena sobre el Derecho de los Tratados, es nulo todo tratado que, en el momento de su celebración, esté en oposición con una norma imperativa de derecho internacional general (Lludgar, 2016).

Con base en lo anterior, el consejo de Estado estipuló que para imputar responsabilidad al Estado que las acciones u omisiones que hayan generado el daño constituyan 
violaciones graves o flagrantes de normas imperativas de derecho internacional de ius cogens, específicamente, delitos de lesa humanidad y/o crímenes de guerra y; que tales violaciones sean atribuibles o imputables, según las normas del derecho interno e internacional, al Estado colombiano (Consejo de Estado, 2016).

La Convención Americana, dispuso que el órgano judicial tiene la competencia para declarar la responsabilidad internacional de un estado parte, por vulneración de la misma, de la convención americana de desaparición forzada de personas y los artículos 8 y 13 del protocolo de San Salvador una vez haya aceptado expresamente (Ramelli, 2009), a su vez los estados asumen de forma individual, el deber de cumplir las sentencias y decisiones de la Corte como lo indica el artículo 68 de la Convención Americana en aplicación del principio pacta sun servanda (Cançado, 2003). Colombia, el 21 de junio de 1985 presentó un instrumento de aceptación por el cual reconoce la competencia de la Comisión Interamericana de Derechos Humanos y de la Corte Interamericana de Derechos Humanos por tiempo indefinido bajo condición de estricta reciprocidad y para hechos posteriores a esta aceptación, sobre casos relativos a la interpretación o aplicación de la Convención, reservándose el derecho de hacer cesar la competencia en el momento que lo considere oportuno (OEA, 2010) Organizacion de Estados Americanos [OEA], 2010).

Por su parte, el artículo 2 del Estatuto de la Corte Interamericana de Derechos Humanos (CIDH) reconoce que la función jurisdiccional de dicho tribunal se regirá por lo establecido en los artículos 61 a 63 de la Convención Americana sobre Derechos Humanos. En estas normas se restringe su competencia al cumplimiento del procedimiento señalado en los artículos 48 a 51 de la misma Convención. Uno de tales requerimientos es que se trate de casos sometidos a su consideración por la Comisión Interamericana de Derechos Humanos. La Comisión sólo puede remitirlos cuando se hayan agotado los recursos de jurisdicción interna, o no se hubiera hecho uso de éstos por inexistencia del mecanismo, constreñimiento del afectado o retardo en la decisión judicial (CIDH, 1979).

En los casos de desplazamiento forzado, la Corte Interamericana de Derechos Humanos ha establecido un sistema de reparación que busca principalmente evitar la propagación del daño en el tiempo sin indicar que sea responsable como tal el Estado 
de dicha afectación, es decir, el hecho que se imponga una condena no necesariamente significa responsabilidad internacional, pues solo se busca que por medio de la Verdad y la Justicia (principios isnaturalistas) se logre la reparación de las víctimas. Este sistema de reparación se muestra apropiado en principio, porque permite reparar en contextos en los que no es posible identificar la plena magnitud del daño y sus responsables. Por lo mismo, implica menores cargas probatorias para las víctimas. Podemos decir, que gracias a la labor conjunta de la Corte y la Comisión Interamericana, numerosas vidas han sido salvadas, recursos y procedimientos de derecho interno se han establecido o perfeccionado para afirmar la obediencia de los derechos humanos, a su vez, leyes nacionales han sido ajustadas con la normativa internacional de protección junto con los mecanismos institucionales de inclusión/exclusión armonizando el sistema democrático y el Estado de Derecho (Rivera y Campos, 2017).

\section{Metodología}

La presente investigación es de tipo de Cualitativo, bajo un diseño documental. Según el autor Bernal (2010), la investigación documental consiste en realizar un análisis de la información que se escribió sobre un tema en específico, con la finalidad de establecer relaciones, así como también las diferencias, las etapas, las posturas o los estados actuales del conocimiento relacionado al tema objeto de estudio, por lo anterior, en el presente estudio se realizó un rastreo académico y jurisprudencial que permitió facilitar la resolución del problema jurídico planteado, sugerir soluciones, explorar sobre la problemática del desplazamiento forzado en Colombia y los fundamentos básicos establecidos por el Consejo de Estado cuando halla participación de actores armados en el conflicto en la violación de los derechos humanos.

\section{Resultados y discusión}

En Colombia los desplazados forzados internos viven en situación de inestabilidad e inseguridad, todo esto aunque existen un cuerpo normativo y legislativo que garantizan su protección, evidencia de esto es la Sentencia T-025 del año 2004 pronunciada por la Corte Suprema, en donde se declara el estado de cosas inconstitucionales, pronunciación que estuvo basada en detener o frenar la violación de los derechos fundamentales de este grupo de personas, además de descongestionar los despachos judiciales. 
Muchos son los individuos que viven una tragedia humanitaria se han visto en la obligación de dirigirse ante los organismos competentes a hacer valer sus derechos, ya que no en más de una ocasión sus derechos son vulnerados por el Estado y es por ello que como manifiesta Saravia (2016) en esta sentencia se agrupan unos 109 expedientes que vienen de distintos lugares de Colombia, solicitando sus derechos a la integridad personal, a la igualdad, a la educación, al trabajo, a la vida digna, al mínimo vital y a la seguridad social y se otorgó protección especial a los niños, a las madres cabeza de hogar y a las personas de la tercera edad.

La omisión por parte del Gobierno y de sus organismos administrativos, en cuanto a el cumplimiento de responsabilidades, establecidas en la Ley y la Normativa que rige los derechos de este grupo de personas y que como consecuencia se les orillaba a vivir en condiciones paupérrimas, así como también, indignas motivaron que se movilizaran hasta la Corte Constitucional para hacer valer sus derechos. (Saravia, 2016).

Este grupo de personas señalaban al Ministerio de Hacienda y Crédito Público, al Ministerio de Salud y trabajo, hoy Ministerio de Protección Social, al Ministerio de Agricultura, el Ministerio de educación, a la agencia Servicio Nacional de Aprendizaje (SENA), la Red de Solidaridad Social, el cual en la actualidad se llama Departamento Administrativo para la Prosperidad Social, así como otros, tal como manifiesta Saravia (2016) por no cumplir con las disposiciones jurídicas de protección y coordinación de la política pública que amparan a personas desplazadas.

Lo cual, es una dura realidad que la población desplazada es la más vulnerable entre las vulnerables del país, debido a las características socio-demográficas propensos a mayores vulneraciones de derechos fundamentales tales como salud, educación, alimentación, garantía efectiva de desarrollo a plenitud de sus vidas en condiciones óptimas y garantizadas por el estado nacional a la mayoría de su población pero que tristemente no son de gozo efectivo, la población desplazada incluso frente a otras poblaciones que son minorías como por ejemplo, afrocolombianos, indígenas y hogares monoparentales. Lo que lleva a afirmar que las víctimas fueron invisibles por el Estado y organismo humanitarios internacionales (Garay, 2009). 
En el acuerdo 185 del ano 2000, se declaró que las personas desplazadas tienen derecho pleno al acceso a los servicios médicos, esto en función a los diferentes tipos de riesgos a los que se enfrentan, con estas acciones el Estado se esfuerza en garantizar y proteger los derechos de las personas consagrados en la Ley como agentes del conflicto y victimas de graves violaciones (Jiménez et al., 2018).

Ante esta situación Cuchumbé y Vargas, (2008) refieren que la ineficiente, la poco, acertada y oportuna atención a las víctimas por parte del Estado, así como de la aplicación de políticas públicas para combatir el fenómeno, amén de un escaso presupuesto, entre otros factores, fue lo que propició que la Corte Constitucional adicionara estos elementos como causal de vulnerabilidad de las garantías constitucionales. Evidenciando dos problemas que limitan el cumplimiento de la sentencia de la corte constitucional: primero, la dificultad que tiene la población desplazada para ser reconocida como víctimas del flagelo y segundo, las actitudes que en momentos tienen los servidores públicos y la ciudadanía, es confundirlos con ciudadanos pobres.

La Corte Constitucional se vio obligada a tomar en cuenta el hecho de que el Estado falló en atender de manera oportuna y efectiva a las víctimas, que la asignación del presupuesto fue paupérrima para poder hacer referente a esta contingencia, además, de que la ejecución de las políticas públicas fue pésima, como causal de vulneración de las garantías constitucionales uniéndose a las relacionadas con las propias de ser desplazados internos forzados.

Todo lo anterior debido a que las víctimas de desplazamiento interno forzados de Colombia al dirigirse a la Corte Constitucional pudieron demostrar que las autoridades encargadas de lo concerniente a las víctimas de desplazamiento como los procedimientos, el fiel cumplimiento de sus derechos, la organización y distribución de la ayuda humanitaria lo hicieron de manera descoordinada y con desconocimiento de lo que debían hacer provocando una serie de dificultades administrativas, así como la ineficacia a la hora de dar respuestas a la demanda de los involucrados en especial en lo concerniente a las áreas de salud, educación y muy especialmente de educación; lo que llevo a la Corte Constitucional, en la sentencia emanada, a afirmar que una gran cantidad de los casos hacían alusión a la privación de los beneficios de la Ley y Normativas que los amparan. 
Las declaraciones del Estado en materia inconstitucional en lo que se refiere a los desplazamientos forzados internos busca su atención prioritaria, para garantizar verdaderamente sus derechos que hasta los momentos no ha sido posible alcanzarlos. Por eso, con el fin de hacer realidad el bienestar de los desplazados, la Corte Constitucional dictaminó que se diera solución a los demandantes, por otro lado, detener la violación de los derechos de los individuos en situación similar a través de directrices dirigidas a cumplir de manera contundente con la Constitución y las leyes por parte de los organismos del Estado (Reales, 2009, como se citó en Saravia, 2016).

La corte constitucional consagro garantías constitucionales que no pueden ser ignoradas ni vulneradas y que son referentes para interpretar todas las demás, ya que consagra la voluntad de la soberanía popular, que descansa en el consentimiento y aceptación de la sociedad como instrumento idóneo para solucionar conflictos (Pérez, 1994, como se citó en Saravia, 2016).

Tal como lo manifiesta Bustamante y Suarez (2009), no cabe duda de que el desplazamiento forzado ha creado una grave y apremiante crisis de derechos humanos, obligando a fortalecer los mecanismos de protección y a replantearse la creación o rediseño de políticas públicas en aras de eliminar o disminuir los obstáculos para desarrollar funciones en el Estado que estén dirigidas a garantizar los derechos de los desplazados. Hasta que se supere la inconstitucionalidad y se protejan los derechos de las víctimas de desplazamiento forzando.

La idea de darle protección mínima a los derechos que tienen los desplazados forzados está reconocida en las sentencias de la corte constitucional, la cual doto, como lo manifiesta Bustamante y Suarez (2009) en el proceso argumentación sólida y fuerte en materia de sus derechos, exigiendo además la garantía material del núcleo esencial de sus derechos.

Cuando Colombia introduce al Sistema Jurídico Colombiano la Convención Americana sobre Derechos Humanos (CADH), dando ejecútese a Ley 16 en el Congreso de la República para el año 1972, comienza a cumplir con los lineamientos establecidos en el instrumento internacional y como lo manifiestan D'janon y Castillo (2019): 
la teoría de la soberanía nacional como limitante para su aplicación fue el momento inicial, entendiendo que las normas, desde todos sus rangos y sobre todo las constitucionales, tienen prevalencia de acuerdo al principio de supremacía constitucional, lo que motivó que adicionalmente se presentara un conflicto interpretativo adicional soportado en la vinculatoriedad/ obligatoriedad en la aplicación de las sub reglas establecidas por la CIDH en materia de respeto y efectividad de los derechos humanos. (p. 172).

En el caso colombiano, la Comisión Interamericana de Derechos Humanos (CIDH, 2007) encontró la responsabilidad del Estado por los hechos ocurridos en el corregimiento de la Rochela, el Tribunal estableció como medidas no pecuniarias de reparación integral, el deber de investigar los hechos que motivaron la transgresión e identificar enjuiciar y sancionar a los responsables, pero además proteger al personal judicial, testigos, víctimas y familiares, por otro lado garantizar la asistencia médica y psicológica, también el educar a los miembros de las fuerzas armadas en relación a derechos humanos. Esto es prueba inequívoca de la evolución que ha tenido la jurisprudencia del Tribunal Interamericano en relación con la reparación integral. Donde se le otorga mucha importancia al principio de la dignidad humana, pero teniendo en cuenta también las disposiciones no monetarias que se hubiesen tomado.

Por lo antes dicho, cabe afirmar, que en la mayoría de los hechos ocurridos por desplazamiento forzado en Colombia fueron por grupos armados ilegales en el cual se advierte que no hubo una conducta omisiva por parte de las autoridades militares y policía, por cuanto se considera que para el personal militar, estaba en la imposibilidad de prever en qué momento los delincuentes atentarían contra la humanidad, honra y bienes de los desplazados, esta teoría ha sido sostenida por el Concejo de Estado desde el año 1998 denominada teoría de la relatividad de la falla del servicio; generando discrepancia frente al manejo de la prueba ante muchos Jueces Administrativos del Estado colombiano, pues para algunos el tema de desplazamiento forzado, sus decisiones son fundamentadas en jurisprudencia de la corte interamericana de derechos humanos y para otros el manejo de la prueba y sus decisiones son fundamentadas en el principio de 
legalidad y respeto por el precedente judicial de su órgano de cierre el honorable consejo de estado de Colombia (Consejo de Estado, 1998).

\section{Conclusiones}

El Estado colombiano ha sido juzgado y condenado en distintas ocasiones por la Corte Interamericana de Derechos Humanos; al analizar cada una de las sentencias proferidas por este Tribunal, y con base a los fundamentos del Derecho Procesal, encontramos prácticas probatorias no convencionales que a nuestro juicio se consideran contrarias a los lineamientos jurisprudenciales, esto hace que sea desfavorable para Colombia al momento de ser sometido a sentencia.

El hecho es que, de conformidad con las disposiciones de la Convención de los Estados Unidos sobre Derechos Humanos (CIDH), tanto sus normas, como la verdad y la justicia, o el uso de principios básicos como "pro homine", pueden utilizarse para justificar este enfoque. Además del reglamento interno de la $\mathrm{CIDH}$, el excelente mecanismo del Tribunal Internacional es la resolución de cumplimiento, de acuerdo con estas resoluciones se dará seguimiento a la adecuada implementación de las medidas dictadas en la Sentencia, lo que equivale al cumplimiento de la obligación de cumplir a cabalidad, la obligación. Inicialmente, es necesario mejorar y tomar las medidas necesarias para evitar que incidentes similares ocurran en el futuro de acuerdo con la obligación de prevenir y proteger los derechos humanos reconocidos en la Convención Americana.

En este orden de ideas, la Corte Interamericana orienta, como garantía de no repetición y dados los delicadísimos hechos contra poblaciones vulnerables, y ante la posibilidad de que persistan en la sociedad actitudes y sentimientos discriminatorios hacia las víctimas del desplazamiento forzado, fortaleciendo los organismos existentes o los que vayan a crear con ese objetivo. 


\section{Referencias bibliográficas}

Bernal, C. (2010). Metodología de la investigación. Edit. Pearson, Colombia. https://abacoenred.com/wp-content/uploads/2019/02/El-proyecto-deinvestigaci\%C3\%B3n-F.G.-Arias-2012-pdf.pdf.

Bustamante, M. y Suárez, C. (2009). Aspectos problemáticos del desplazamiento frente a los derechos a la salud, educación, vivienda y proyectos productivos". En: Derechos de la población desplazada (estudio de caso en la ciudad de Medellín). Muñoz Restrepo, Alba [et al.]. Edit. Universidad de Medellín, Medellín, 2009, págs. 23-38.

CIDH. (1979). Resolución $N^{\circ} 448$ adoptada por la Asamblea General de la OEA en su noveno periodo de sesiones, celebrado en La Paz, Bolivia. https://www. corteidh.or.cr/estatuto.cfm.

CIDH. (2007). Caso masacre de la Rochela vs Colombia. Numero 11.995 https://www. corteidh.or.cr/docs/casos/articulos/seriec_163_esp.pdf.

Cançado, A. (2003). Prólogo en Memoria del Seminario El Sistema Interamericano de Protección de los Derechos Humanos en el umbral del siglo XXI (San José de Cota Rica 23 y 24 de noviembre de 1999), Tomo I. $2^{\text {a }}$ ed. Pp. XXI a XXIX. http://www.corteidh.or.cr/docs/libros/Semin1.pdf .

Consejo de Estado (2016) Sala de lo Contencioso administrativo, sección tercera, CP Jaime Orando Santofinio Gamboa, radicado: 52001-23-31-000-199800565-01 (34.791) actor Rubén Leonardo Bolaño y otros vs NaciónMinisterio de defensa - Ejercito Nacional. http://consejodeestado.gov.co/ documentos/sentencias/10-03-2016_52001233100019980056501.pdf.

Consejo de Estado (1998) Sala de lo Contencioso administrativo, sección tercera, CP Jesus Carrillo Ballestero, expediente $N^{\circ} 11837$ actor Luis Fernández 
Vega y otros vs Nación-Ministerio de defensa-Ejercito Nacional. https:// sidn.ramajudicial.gov.co/SIDN//DOCTRINA/TEXTOS_COMPLETOS/ ANTOLOGIAFINAL/SECCION_TERCERA/SECCION_TERCERA_ TOMO_B/CE-SEC3-EXP1998-N11837.pdf.

Corte Constitucional de Colombia (2014). Informe Sala Especial de Seguimiento a los 10 años de la declaración del Estado de Cosas Inconstitucional. http://www. corteconstitucional.gov.co/T-025-04/Proceso $\% 20 \mathrm{de} \% 20$ Seguimiento $\% 20$ $10 \% 20 \mathrm{a} \% \mathrm{C} 3 \% \mathrm{~B} 1 \mathrm{os} . \mathrm{PDF}>$.

Cuchumbe, H. y Vargas, B. (2008). Reflexiones sobre el sentido y génesis del desplazamiento forzado en Colombia. Universitas humanística no.65. (Pp. 173-196). Bogotá - D.C Pontifica Universidad Javeriana de Cali y Universidad del Valle. https://www.redalyc.org/pdf/791/79106509.pdf.

D'janon, M. y Castillo, S. (2019). Mecanismos judiciales para asegurar la efectividad de las sentencias emitidas por la Corte Constitucional de Derechos Humanos en casos contra Colombia. Editor Duarte, R. (2019). En Lenguaje jurídico, filosofía del derecho y teoría jurídica. Pp 167-184. https://repository. unilibre.edu.co/bitstream/handle/10901/16012/Libro_Lenguaje_juridico. pdf?isAllowed $=\mathrm{y} \&$ sequence $=1$.

Garay, L. (2009). Tragedia humanitaria del desplazamiento forzado en Colombia. Estudios Políticos. ISSN 0121-5167 No 35, Medellín, julio-diciembre de 2009: pp. 153-177. https://revistas.udea.edu.co/index.php/estudiospoliticos/ article/view/5160.

Jiménez, A., Huerta, M., y Quintero, M. (2018). Limites Jurídicos que obstaculizan el Acceso a la Administración de Justicia por vía administrativa, para la reparación de las víctimas del desplazamiento forzado. Bogotá. D.C (pp. 1 al 96) Universidad Libre de Colombia, https://repository.unilibre. 
edu.co/bitstream/handle/10901/17674/MONOGRAFIA\%20FINAL. pdf? sequence $=1 \&$ isAllowed $=\mathrm{y}$.

Lludgar, E. (2016). "La Doctrina de la Corte Interamericana de DDHH, y las Resoluciones de la Comisión Interamericana de DDHH, como fuentes y formas de protección de los Derechos Fundamentales". http://www. corteidh.or.cr/tablas/r35244.pdf .

López, M. (2013). Exploración conceptual de la responsabilidad patrimonial del Estado frente al desplazamiento forzado. Colegio mayor de nuestra señora del rosario. Bogotá D.C.

Molina, C. M. (2005). Fundamentos constitucional y legislativo de la responsabilidad patrimonial del Estado: antecedentes dogmáticos-históricos y legislación vigente. Opinión Jurídica, 4(7), 43-66. Recuperado a partir de https:// revistas.udem.edu.co/index.php/opinion/article/view/1305

OEA. (1969). Convención Americana sobre Derechos Humanos suscrita en la conferencia especializada interamericana sobre derechos humanos (b-32). http://www.oas.org/dil/esp/tratados_B-32_Convencion_Americana_sobre_ Derechos_Humanos_firmas.htm\#Rep\%C3\%BAblica\%20Dominicana:

ONU. (2010). Informe anual de la comisión interamericana De derechos humanos. https://www.cidh.oas.org/annualrep/2010sp/indice2010.htm.

Ramelli, A. (2009). El derecho internacional humanitario ante la Corte Interamericana de Derechos Humanos. En Anuario mexicano de Derecho Internacional Volumen IX. (Pp. 35-68). México D.F.: Universidad Nacional Autónoma de México.

Reales, C. (2009). Design and Implementation of the Orders Issued in Decision T-025 of 2004: An Assessment of the Process, judicial protection of internally 
displaced persons: the Colombian experience. En: Arango-Rivadeneira, R. (coord.). Edit. The Brookings Institution-University of Bern. pp. 49-88.

Rivera, C. y Campos, V. (2017). Política pública educativa centrada en la tecnología. El caso del programa habilidades digitales para todos en el estado de puebla y su efecto en la formación de cohesión social. En Chirinos, Y., Ramirez, A., Rodríguez, E., Pérez, C. y Camejo, L. (2017). (Eds). Tendencias en la Investigación Universitaria. Una visión desde Latinoamérica. Volumen 1. P 232- 255. https://www.alinin.org/alininwp/wp-content/uploads/2019/06/ PRIMER-libro-de-tendencias-en-investigacion-voll.pdf.

Saravia, (2016). El papel de la corte constitucional colombiana ante la asistencia estatal a los desplazamientos internos forzados por la violencia. https://addi.ehu. es/bitstream/handle/10810/18421/TESIS_SARAVIA_CABALLERO_ JACKELINE\%20CECILIA.pdf?sequence=1\&isAllowed=y.

Vidal, R. (2007). Derecho global y desplazamiento interno. Edit. Pontificia Universidad Javeriana, Bogotá D.C., 2007. 